\title{
"Apparently I've Got Low Self-Esteem": Schoolgirls' perspectives On a School-Based Public Health Intervention
}

Sofia Kvist Lindholm and Karin Zetterqvist Nelson

\author{
Linköping University Post Print
}

\section{Tweet}

N.B.: When citing this work, cite the original article.

Original Publication:

Sofia Kvist Lindholm and Karin Zetterqvist Nelson, "Apparently I've Got Low Self-Esteem": Schoolgirls' perspectives On a School-Based Public Health Intervention, 2014, Children \& society.

http://dx.doi.org/10.1111/chso.12083

Copyright: Wiley: 24 months

http://eu.wiley.com/WileyCDA/

Postprint available at: Linköping University Electronic Press

http://urn.kb.se/resolve?urn=urn:nbn:se:liu:diva-113544 


\title{
"Apparently I've got low self-esteem": Schoolgirls' perspectives on a school- based public health intervention
}

\begin{abstract}
This article focuses on a psycho-educational programme, DISA, currently practiced in the Swedish schools to prevent girls from developing depressive symptoms. We draw on group interviews with schoolgirls to explore how they describe DISA and how an understanding of the programme is constructed through their arguments. We demonstrate how the girls' version of DISA highlights a contradiction in the intervention that is traceable to the theoretical underpinnings of the programme and the mix of traditions - treatment and prevention - that constitute the intervention. We discuss problematic aspects of DISA and outline implications for policy practice.
\end{abstract}

\section{Introduction}

A widespread concern for a deterioration of children's mental health and its public health implications has prompted implementation of universal psychotherapeutic education programmes in Swedish schools (SBU, 2010) similar to what has taken place in many other countries (Coppock, 2011). These universal school-based interventions are practised for children in general, regardless of their individual needs or problems, the intention being to promote their emotional wellbeing and reduce their risks of developing mental health problems (SBU, 2010). Arguments underlying a universal approach draw on principles of the 'preventive paradox' (Rose, 1992), which points to the difficulty in predicting which individuals will develop specific health problems and suggests that reducing small risks within the general population has greater public health potential (e.g., Merry et al., 2012). Furthermore, a universal preventive approach is argued to help circumvent the practical difficulties and stigmatizing consequences of interventions that identify and target individuals (ibid.; SBU, 2010). However, critical voices have emerged. Coppock (2011) suggests that these universal public health interventions are not necessarily less stigmatizing, because they persist in labelling young people as 'at risk' and approaching mental ill-health as an issue of individual deficiencies (Coppock, 2011). Based on theories of governmentality, Petersen and Lupton (1996) argue that public health, as an expert discourse, shapes the lives of individuals. Although the focus is not on individual needs, but on public health and what favours the interest of the many, it still has implications for individuals, because they "face the task of having to monitor, regulate and change (that is, refashion) themselves to avoid, modify, control and eliminate behaviours and situations deemed "risky"' (Petersen and Lupton, 1996:20). In a similar vein, Ayo (2012) points to how health promotion starts from a structural view of health, but often consists of activities that focus on individuals' self-regulation (Ayo, 2012). While these critical studies are helpful in identifying problematic contradictions in public health interventions, they are played out on a societal macro-level and say nothing about how contradictions are produced when a programme is designed and practised. Nor do they elaborate on 
individuals' roles as social actors who both enact and resist norms and regulations (Valentine, 2011). The present study discusses contradictions in a public health intervention called DISA, but starts from a micro-level, taking participants as the source of inquiry, and sheds light on the very production and negotiation of such contradictions. The study is part of a broader research project on children's perspectives on school-based public health interventions and is based on a discourse analysis of group interviews with DISA participants (for an observational study of DISA sessions, see Wickström, 2013).

The DISA intervention has seen wide distribution within Swedish schools. It was initiated by the Centre for Public Health, at Stockholm County Council, to address concerns about teenage girls' mental health and is based on the view that this group is 'at risk' for developing depression (Treutiger, 2006). The official stated intention of DISA is to be a preventive intervention, not a treatment (DISA manual, 2010, p. 3, 13), suitable for teenage girls in general (Thomas, 2013; Treutiger, 2006). When analysing the interviews, we were struck by the mismatch between the official intention of DISA and how participants spoke about their experiences of DISA more in terms of treatment for predefined problems that presumes a participant with a specific problem profile. The aim of the current article is to present an in-depth exploration of this mismatch. The unfolding analysis will specify that the intervention brought with it expectations that the girls should identify with already having the very problems the intervention was intended to prevent. We argue that the problem lies in an inherent contradiction in the intervention - a contradiction that derives from DISA's clinical roots, on the one hand, and its current universal preventive approach of targeting teenage girls in general, on the other. The results highlight the inadequacy of applying techniques designed for treatment in a programme intended to be preventive. We argue that the tendency among psycho-educational programmes to apply universal preventive approaches and adopt non-clinical terminology may in fact create such contradictions, in which the aims and scope of an intervention are not in alignment with its essential content.

The article is divided into two parts. First we explore how an understanding of the programme is constructed through the girls' descriptions and arguments, which contradicts the official version of DISA. In order to make sense of the girls' arguments, we then shift focus to examine the programme they have taken part in, tracing the contradiction back to DISA's theoretical underpinnings and the mix of traditions treatment and prevention - that constitute the intervention. We discuss problematic aspects of DISA and outline implications for policy practice. Before presenting methodology, we will introduce the DISA programme.

\section{DISA}

A DISA course consists of ten structured sessions set by a programme manual. The manual originates from the American psycho-educational programme 'Coping with Depression' (CWD), designed as depression treatment based on principles of cognitive behavioural therapy (Lewinsohn and Clarke, 1984). The manual has been adapted many times (e.g., 'Adolescents Coping with Depression', 'Adolescents Coping with Stress') and translated into Swedish to constitute the DISA intervention (DISA Manual, 2010). Since DISA was introduced, the name has been changed. Originally an acronym for 
'Depression In Swedish Adolescents' (Treutiger, 2006), it is now commonly spelled out as Din Inre Styrka Aktiveras (Activate your inner strength) and marketed as a course that will activate girls' inner strength (Thomas, 2013).

The starting point of the intervention is health statistics reports showing that more girls than boys report depressive symptoms. These statistics are used to define teenage girls as a group 'at risk' for developing depression and as a suitable target group for the intervention (Treutiger, 2006). The approach of targeting teenage girls in general is furthermore based on principles underlying the preventive paradox (cf., Rose, 1992), and on the assumption that this approach is less stigmatizing than interventions targeting individuals (Treutiger, 2006).

Prior to large-scale implementation of DISA in Swedish schools, a controlled outcome study was conducted, suggesting that the intended effects of preventing girls from developing depressive symptoms had been achieved (Treutiger, 2006). Based on these findings, DISA has been marketed as evidence-based, a claim that was questioned in a review by the Swedish Council on Health Technology Assessment (SBU). The scientific evidence related to DISA is deemed weak and further studies are recommended (SBU, 2010).

\section{Methodology}

The present study draws on the field of interdisciplinary childhood studies, in which young people are positioned as social actors. It implies acknowledging that school children are not merely receiving education, but negotiating its meaning and the circumstances it gives rise to, as well as taking part in the construction of its actual practice (James, 2010). One point of departure is that children's voices and experiences make an important epistemological contribution to our understanding of the social world (James and Prout, 1990; James, 2007). As social actors; the school girls are thus not merely understood as recipients of a course like DISA, but as actively relating to and negotiating its meaning and form. Group interviews have been carried out with DISA participants to explore what they say about DISA and how an understanding of the programme is constructed through their arguments. Childhood researchers James (2007) and Spyrou (2011) argue that an analysis of children's voices needs to consider that these voices do not only reflect children's experiences, but are structured by the discursive context in which they are collected and heard. Here, discourse analysis was applied to enable taking the situated and broader discursive context into account (Wetherell, 1998; Verkuyten, 2003).

\section{Empirical data}

The empirical data consist of eight group interviews with 32 schoolgirls from six DISA courses that started during autumn 2009 and spring 2010 in a relatively small municipality in Sweden. The number of participants in the interview groups ranged from three to five students from the DISA courses, which consisted of five to eleven participants per course. The participants, i.e. girls 12-14 years of age, as well as their parents received written information about the research project. In addition, the 
participants were given verbal information regarding confidentiality and informed consent. Out of a total of 54 DISA participants, consent was received from 32 girls and their parents. Eight girls declined participation, as they were not in school at the time of the interview. The rest (fourteen students) indicated no particular reason for declining participation. But according to the interviewees from their particular DISA groups, the girls who declined participation had expressed great dissatisfaction with DISA during the course and complained about having to attend DISA sessions. Their perspectives could have enriched the study by adding possible insights into the intervention, and thus their absence constitutes a limitation.

The interviews were semi-structured. The girls were asked to describe and give their opinions on the course as well as to describe what they feel affects their wellbeing. Different follow-up questions were posed depending on what the girls referred to and stressed during the conversations. The interviews were audio-recorded and lasted for approximately one and a half hours. To facilitate transcription and interpretation of the talk, we also asked participants' permission to video-record the interviews. All interviews, except one, were video-recorded. The interviews were transcribed verbatim in Swedish (capitals indicate emphasis and /.../ indicates talk omitted from the excerpt). For ethical reasons, all interviewees quoted in the present article have been given pseudonyms. Besides the interview data, the empirical material consists of the programme manual and field notes from a DISA instructor course. All excerpts used in the article have been translated from Swedish to English.

\section{Analytical procedure}

Discourse analysis is based on social constructionism and focuses on how experiences, events and situations are given meaning through text and talk. The analytical focus is set not only on content but also on form - on how something is written/said. Text and talk are not considered to mirror reality, but rather to construct versions in which the meaning of something may be reproduced, but also changed (Wetherell, 1998). In the present study, the analysis started from the way in which participants themselves oriented to talk. Verkuyten (2003) argues that such an approach helps researchers avoid applying unreflective categories to the material. The analysis was initiated with a focus on what the girls talked about when describing and evaluating different aspects of the course, as well as on how they spoke about these things. We found that the girls repeatedly mentioned DISA's focus on 'negative thoughts' and problems associated with negative thoughts. Furthermore, the ways in which they rhetorically managed the issue, often distancing themselves, indicated a conflict of some kind. We then analysed more closely how they formed arguments in these situations and how DISA was constructed through their arguments. When contextualizing their talk, we were guided by what the girls themselves referred to in their arguments, and questions like 'Why is this utterance here?' and 'Why do their arguments make sense in this situation?'

(Wetherell, 1998; Verkuyten, 2003). Wetherell (1998) argues that such questions enable an analysis of both the situated context (the on-going interview conversation) and the historical, cultural and social context in which the content and history of the arguments are being scrutinized (Wetherell, 1998, p. 403-5; see also Verkuyten, 2003, p. 151). In order to make sense of the girls' arguments, the analysis of talk was followed by an 
analysis of how the aspects the girls referred to were explained in the programme manual and the DISA instructor course.

\section{Constructing DISA}

The following sections explore how DISA is constructed in the girls' descriptions and arguments. We discuss the mismatch between the girls' version and the official version of DISA.

\section{What is DISA?}

All interviews were initiated with the question 'What would you say DISA is?' Looking at the participants' responses, a recurrent pattern emerged in which they talked about a focus on changing their negative thoughts. They described various techniques they had been taught for handling negative thoughts, repeating specific phrases and wordings. They typically said "you should search for negative thoughts" (Emilia, Group 2) and "what you should do to sort of counteract negative thoughts and such things" (Lovisa, Group 4) and "you should sort of throw out your negative thoughts and change them into positive thoughts" (Isabel, Group 6). The repeated phrases used by the girls demonstrate a way of talking about thoughts as things that are concrete and individually manageable, that ought to be searched for, counteracted, and changed. The girls' descriptions of DISA correspond well with the programme manual, which is dominated by exercises dealing with changing participants' negative thoughts and instructs participants to "catch yourself thinking negatively at least once a day and try to 'replace' that thought with a positive thought" (DISA manual, p. 32). When the girls described DISA's focus on changing their negative thoughts, 'negative thoughts' are emphasized as being the source of problems, as generating negative spirals. One girl, Elvira, puts it this way when explaining the line of thinking in DISA:

\section{Excerpt 1, Group interview 3}

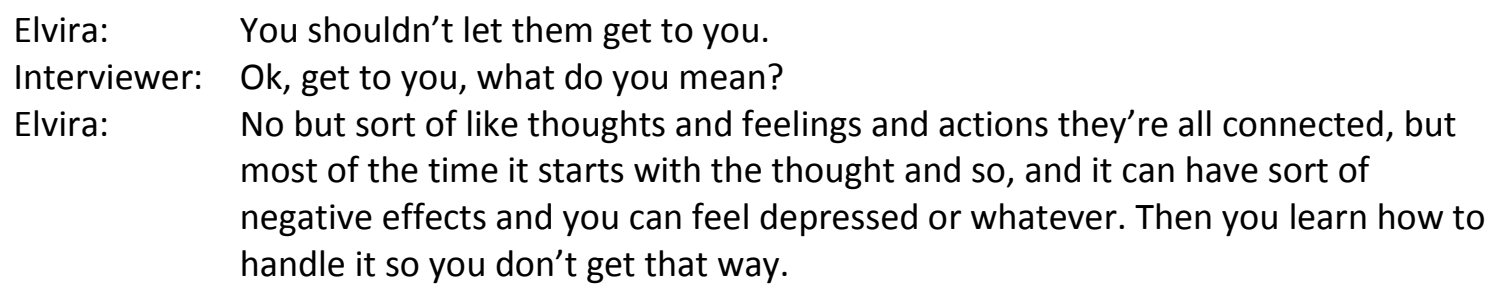

Here we see how "negative thoughts" are talked about as "them", as agents that can "get to you" (line 1) and furthermore constructed as being the source of emotional problems (line 4, 5). During the interviews, the participants referred to this focus on negative thoughts and their associated problems several times. But the ways in which they rhetorically managed the issue of "negative thoughts", often by distancing themselves, showed that this focus constituted a dilemma. This will be discussed in the next section. 


\section{Whose problems?}

In one interview, near the end, after various aspects of the course had been discussed, the interviewer asks the group if they would recommend DISA for others. When responding, the girls refocus the question, making it into an issue of to whom the course is offered.

\section{Excerpt 2, Group interview 1}

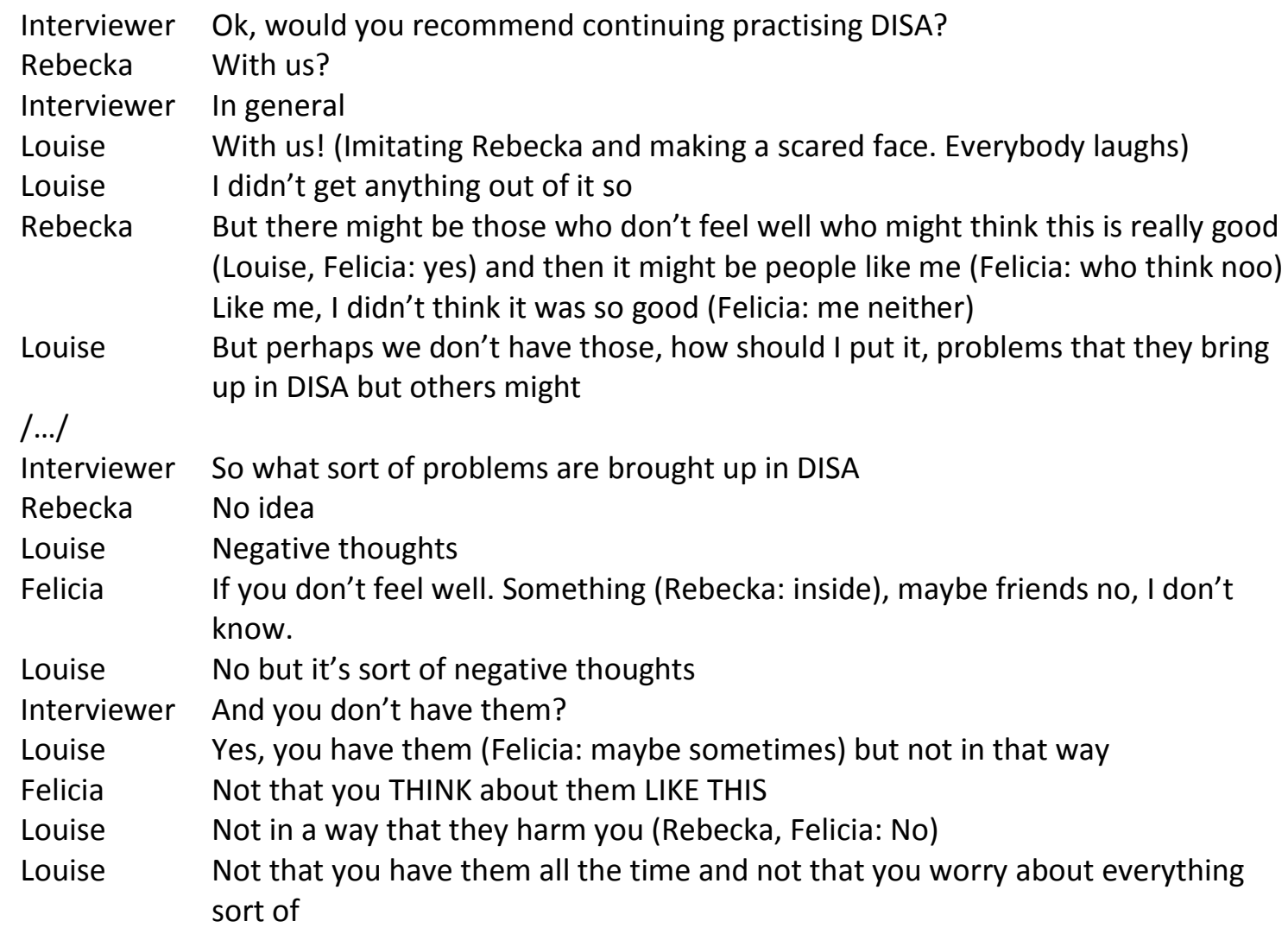

The official version states that DISA is a preventive intervention, not a treatment, suitable for teenage girls in general. The girls' arguments above, however, demonstrate that they talked about DISA more in terms of treatment, which presumes a participant with a specific problem profile. The arguments presented above are given in response to the question of whether they would recommend continuing the DISA programme. However, through their arguments, they change the question to one of who would benefit from it. Rebecka initiates by creating a dichotomy between herself and others who might appreciate DISA. She argues that there might be people who really like DISA, but these are people who 'don't feel well' (line 6). She distances herself by saying "and then it might be people like me, I didn't think it was so good" (line 8, authors' italics). Implicit in her argument is that she feels well and therefore did not appreciate the course. Felicia supports Rebecka's line of argument by filling in her sentences (line 7,8). Louise continues Rebecka's argument by introducing the term 'problem' to clarify why they did not appreciate DISA. She positions their group as not having the problems that are dealt with in the course, saying 'But perhaps we don't have those, how should I put it, problems that they bring up in DISA, but others might' (line 
9-10, authors' italics). Louise stresses that the problems addressed were negative thoughts (line 14, 17), and together with Rebecka and Felicia she then differentiates between negative thoughts that they can identify with and the problematic negative thoughts that are addressed in the course - negative thoughts that occupy your mind and harm you (line 19-23).

Together they construct DISA as a course for a participant 'who doesn't feel well' (line $6,15)$, someone who has problems with 'something inside' (line 15), someone who is 'harmed' by her negative thoughts (line 21), someone who thinks negative thoughts 'all the time' and 'worries about everything' (line 22). They position themselves as not being suitable DISA participants, the reason being that they do not identify with having these problems (line 7-10, 19-23).

The course focus on changing participants' negative thoughts and their associated problems were used several times by the participants as a basis for opposing specific exercises or opposing the whole course. Two exercises were specifically mentioned: the "15 minutes" of worrying time they could try to set aside daily, thinking about their negative thoughts, and the diary exercise in which they should register their negative thoughts and rate their mood on a daily basis. Not all participants, however, were opposed to the latter exercise or rejected the problems addressed in the course. In the following excerpt, Elvira responds to the question of what she thought was good about the exercise.

\section{Excerpt 3, Group interview 3}

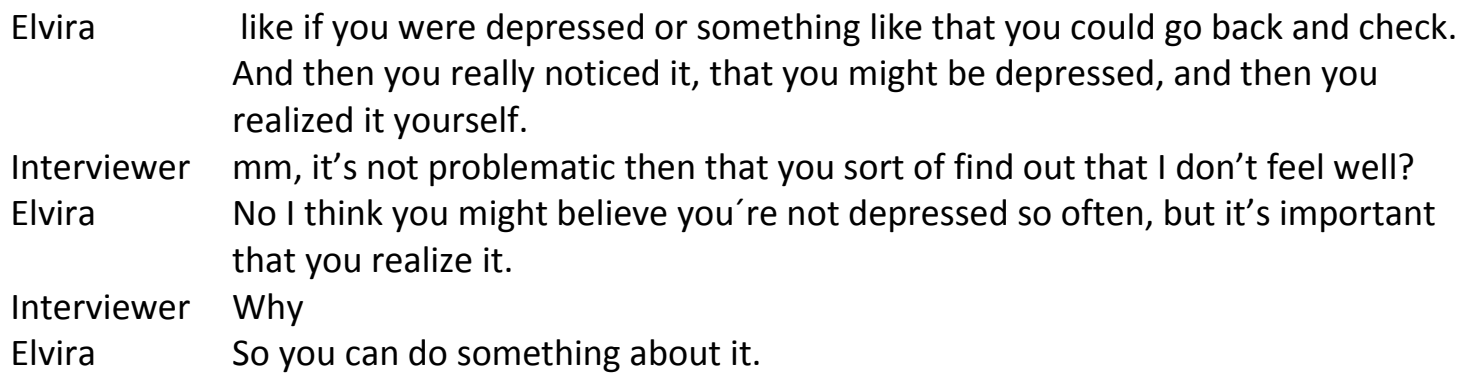

Elvira describes how it was helpful in making participants 'really notice' and 'realize' that they 'might be depressed' (line 2). When asked whether this could be a problem, she replies that realizing one is depressed is important for being able to 'do something about it' (line 5, 6,8). This is a different example of how the participants' arguments construct DISA as treatment rather than prevention. In contrast to many other participants, Elvira does not use the problems associated with the exercise as a basis for opposing it or for positioning herself as not being a suitable DISA participant. Instead she appropriates it.

When analysing accounts of the focus of the course, a particular paradox was highlighted. We will see an example of this when the participants in one group are asked to develop arguments presented earlier in the interview. One of the participants, Isabel, has argued that because DISA is only practised for girls and not boys, "it feels like it's only girls who have problems" and that it is so "focused on stuff", clarified as "the spiral, negative thoughts" and "then you don't get what you're doing there" 
(authors' italics). The interviewer picks up on these arguments and Isabel and Jennifer further develop them.

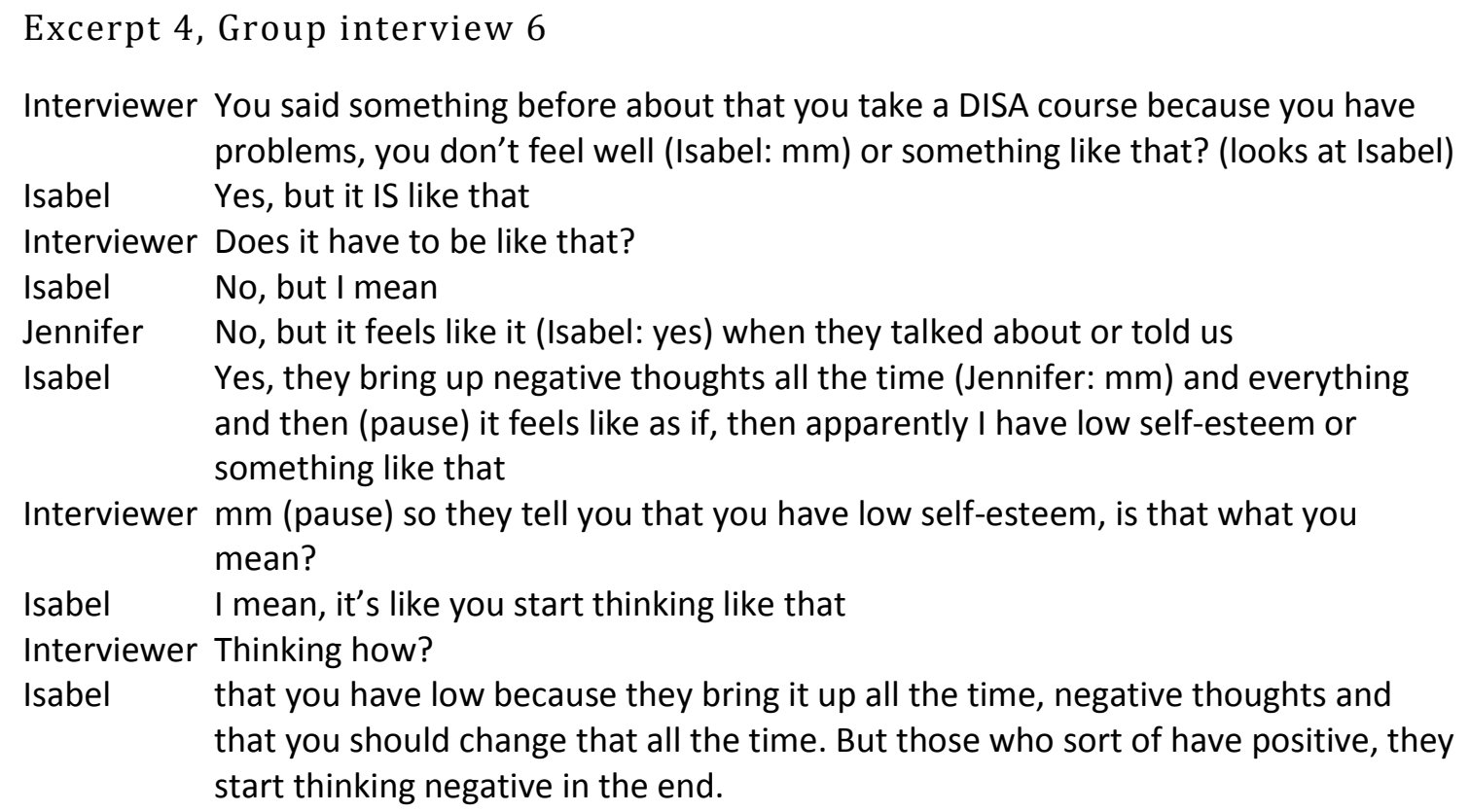

When the interviewer asks about arguments previously made by Isabel, she confirms (line 2) and defends these arguments by saying 'yes, but it $I S$ like that' (line 3, authors' italics). When asked whether it has to be the case that a course participant has problems or is not feeling well in order to take the course, both Isabel and Jennifer answer 'No, but' (line 5,6, authors' italics) and form arguments for why it 'feels like' this is the case (line 6,8). They refer to a repeated focus on low self-esteem, negative thoughts and on changing participants' negative thoughts (line 7, 14-15). In these arguments, they both distance themselves from the instructors. Jennifer says 'it feels like it when they talked about or told us' and Isabel describes how 'they bring up negative thoughts all the time' (line 6-7, authors' italics) and that "They bring it up /---/ that you should change that all the time' (line 14-15, authors' italics). Through these formulations, they stress that they have no control over the definition of problems. Isabel's argument "then apparently I have low self-esteem or something like that" (line 8-9, authors' italics) highlights a paradox: it is not up to her to define what problems she is having. They are defined for her by the course. In other words, she is positioned as having low self-esteem. DISA is hereby constructed as a course that conveys predefined problems and furthermore ascribes these problems to its participants (line 8-9, 14-15).

To sum up, according to the girls' arguments, the course pre-defines problems for participants to identify with and work to rid themselves of, without any specific consideration for their individual needs or problems. This highlights the problematic nature of DISA's universal approach. The official version of DISA states that it is a preventive intervention, not a treatment, suitable for teenage girls as a group. In the girls' arguments, however, DISA is construed as treatment rather than prevention. They point out that the course presumes a specific problem profile: a participant who identifies with having low self-esteem, feeling depressed and having compulsive negative thoughts and being harmed by them. In order to make sense of the girls' 
arguments, we will now continue with a closer examination of the programme itself. In the next section, we will analyse how the issues the girls referred to are described in the programme manual, and in a DISA instructor course, and how the girls' arguments relate to these descriptions.

\section{The programme manual and instructor course}

In the DISA manual, the methods practised are defined as prevention. The exercises are described as allowing participants to "prevent depressive symptoms" and build up "immunity to depression and feeling low" (DISA manual 2010, p. 3, authors" italic), not intended to make them identify with having problems such as low self-esteem, depression and compulsive negative thoughts and related harm. However, when explaining the theoretical framework for the methods practised in the course, the manual refers to the "field of therapy" and to depressed adolescents. It defines their 'depressive, negative/irrational thoughts (Beck and others, 1979)' as a reason for their depression (DISA manual 2010:3). This highlights the clinical origin of the programme, where its forerunner was developed for depression treatment that involves teaching cognitive-restructuring techniques. When the programme manual moves on to describe how this theoretical starting point is used as a basis for the DISA intervention, it states that the course will give participants "practice in different cognitive methods that allow them to reduce their negative thoughts and by doing so reduce their risk of developing depression" (ibid.). Use of the words risk and developing highlights the intended transformation of treatment into prevention (cf. Mrazek and Haggerty 1994).

To clarify, the cognitive methods applied in the course - to identify and change participants' negative thoughts - were originally designed for treatment, but are now being practised as prevention for teenage girls as a group. The problem is that treatment and prevention use different procedures when defining suitable recipients. In treatment, the intervention is designed for a specific health problem and a recipient who commonly is seeking help because he/she is experiencing this problem. In prevention, the aim is to keep a health problem from occurring, and the recipients are targeted because they have an expected risk of developing such a problem (Mrazek and Haggerty, 1994). Thus, the DISA course teaches cognitive-restructuring techniques originally designed to help a depressed individual overcome his/her depression by identifying and changing his/her depressive, irrational/negative thoughts - assumed to be one significant cause of his/her depression. The course, however, does not target a clinically depressed group, but teenage girls in general. In line with the criticism Petersen and Lupton (1996) offer in relation to public health interventions, DISA is not justified by the girls' individual problems or needs 'here and now', but by a focus on preventing potential problems and promoting public health. Aggregated health statistics are used to define teenage girls as a group "at risk" for developing depression and this becomes the justification for and starting point of the intervention, together with assumptions that targeting teenage girls as a group is less stigmatizing and will prevent more cases of depression.

During the DISA instructor course, the clinical origins of the methods used in the course are not taken up as an issue. The lecturer explains the manual by giving an overview of the content, and by dividing the sessions into three phases. The first 
sessions are described as being aimed at making the girls aware, the subsequent sessions at questioning and the last at preventing. These stages are in accord with a model used in behavioural therapy to make individuals aware of their problem, so that they will be ready to change their behaviour (see The Stages of Change Model, Prochaska and Velicer, 1997). But this reveals another contradiction. DISA is intended to be a preventive intervention, not treatment (DISA manual 2010, p. 3, 13). Despite this, participants must first go through phases of becoming aware and questioning, before entering the phase called preventing. Through this, and with the exercises applied, a DISA participant becomes a clinical subject - someone who needs to become aware of her problems and question herself. The three phases are described in the instructor course as a means for instructors to grasp the bigger picture of the course and its sessions. This contradiction between the clinical and the preventive, however, is never brought out into the open. As a consequence, the responsibility for dealing with this contradiction is passed on to the instructors and, in the long run, to the course participants.

In conclusion, the contradictions found by comparing how the girls spoke about DISA with the expressed intentions of the programme are traceable to the theoretical underpinnings of the programme and the mix of traditions - treatment and prevention that constitute the intervention.

\section{Concluding discussion}

The DISA programme targets girls and aims at preventing depressive symptoms and depression. In the programme manual, depression is described as having multi-factorial causes of both a structural and individual character. One cause - depressive negative/irrational thoughts - was chosen as the main focus of the programme. The problem definition is thereby narrowed to a focus on identifying, counteracting and changing individual thoughts. In this way, DISA is in accord with Ayo's (2012) general critique of health promotion. He argues that, despite departing from a structural perspective, health problems are often tackled using strategies that focus on individual self-regulation, thereby neglecting the social and structural determinants of health (Ayo 2012). The girls' ways of talking about the intervention demonstrate that the implementation of a programme in school that uses a repeated focus on problems and a narrow problem definition, focused on the individual, is problematic. The present analysis demonstrates that the intervention brought with it expectations that the girls should identify with already having the very problems the programme was intended to prevent, and that they should, at the same time, search for the cause within themselves, the cause being their negative thoughts. In this way, the girls, and their assumed negative thoughts, become both the source of and solution to their problems.

The programme was initially named "Depression in Swedish adolescents". Following what Coppock (2011) refers to as a 'normalizing process' among psycho-educational programmes - moving away from a medical perspective and adopting non-clinical terminology - DISA is, currently, marketed as an acronym for "Activate your inner strength". The current name contrasts sharply with the strategies used in practice, where the girls are expected to identify with having low self-esteem and feeling depressed and 
to search for the cause of these problems within themselves: their negative thoughts. Coppock (2011) argues that psycho-educational programmes have made efforts to adopt non-clinical terminology and apply universal, preventive approaches so as to be less stigmatizing. However, the present results indicate that if a change of name and recipients is not accompanied by an equal change in content, this may instead be counterproductive, as it will obscure contradictions in the intervention. A method designed for treatment is based on a recipient who is diagnosed with a disease, disorder or health problem and who is in need of the strategies here and now in order to improve. When a preventive programme is based on treatment, there is a risk that the notion of the recipient as patient will tag along, even if the intention has changed to one of prevention and the intervention is marketed without any clinical attributes. The question may even be raised as to whether DISA, with its predefined problems and narrow problem definition, is counterproductive in that the intervention, in practice, reinforces stereotypical notions of girls as depressive and as having low self-esteem as well as reducing their health problems into a question of individual deficiency.

The study highlights the problematic aspects of using health statistics as a starting point for designing and practising preventive interventions. There is a need to separate 1) the general level, where health statistics are used to follow trends in public health, from 2) the individual level, where health interventions are designed and practiced, because all programmes will inevitably deal with individuals. Even if the participants belong to a general risk group, in practice a programme always encounters individuals who are not necessarily experiencing the problems they have been associated with on a general level.

The study demonstrates the need to compare the aims and scope of a programme with its executive content in order to identify possible contradictions, as these contradictions may be associated with several problems and dilemmas. However, it also indicates that contradictions may be difficult to identify when marketing does not highlight but rather hides them. Moreover, it shows that participants' ways of making sense of interventions may help in identifying contradictions and paradoxes that are not identifiable using traditional evaluation approaches focused on outcome measures or by analysing compliance with a method.

While the study sheds light on an inherent contradiction in DISA, it does not illuminate how the girls handle the intervention in practice. A study on children's agency in DISA sessions (Wickström, 2013), however, demonstrates that participants use strategies to transform the intervention and concludes that the cognitive methods applied could be replaced by exercises dealing with personal interaction. In a similar vein, the present study does not support the DISA intervention in its current form. The results demonstrate the inadequacy of applying techniques designed for treatment in a programme intended to be preventive. They also highlight the importance of adopting a wide problem definition that acknowledges the social and structural determinants of health, not only in theory, but also in the intervention strategies practised. Furthermore, the study suggests that if a universal preventive approach is chosen as a measure of promoting public health in the school, the programme should be adaptable to individuals - their current needs and experienced problems - rather than reliant on predefined problems and strategies. 


\section{Acknowledgement}

The article reports on research funded by the Swedish National Institute of Public Health (HFA 2008/213). The study was approved by the Regional Ethical Review Board of Linköping University (Reg. no. 181-09).

\section{References}

Ayo N. 2012. Understanding health promotion in a neoliberal climate and the making of health conscious citizens. Critical Public Health 22: 99-105.

Beck AT, Rush AJ, Shaw BF, Emery G. 1979. Cognitive therapy of depression. New York: Guilford Press.

Coppock V. 2011. Liberating the Mind or Governing the Soul? Psychotherapeutic Education, Children's Rights and the Disciplinary State. Education Inquiry 2: 385-399.

DISA manual. Lindberg L, Jonze V, Treutiger BM, Koertge J et al. 2010. DISA: En metod att förebygga stress och depressiva symtom bland tonårstjejer.

Gruppledarmanual. Available at http://www.folkhalsoguiden.se/DISA [Accessed 1 September 2011].

James AL. 2010. Competition or integration? The next step in childhood studies? Childhood 17: 485-499.

James A, Prout A. 1990. Constructing and Reconstructing Childhood. Falmer Press: Basingstoke.

James A. 2007. Giving Voice to Children's Voices. Practices and Problems, Pitfalls and Potentials. American Anthropologists 109: 261-272.

Lewinsohn PM, Clarke GN. 1984. Group treatment of depressed individuals: the 'Coping with Depression' course. Advanced Behavioural Research Therapy 6: 99-114.

Merry SN, Hetrick SE, Cox GR, Brudevold-Iversen T, Bir JJ, McDowell H. 2012. Psychological and educational interventions for preventing depression in children and adolescents (Review). Evidence-Based Child Health: a Cochrane Review Journal 7: 1409-1685.

Mrazek P, Haggerty R, eds. 1994. Reducing risk for mental disorders: Frontiers for preventive intervention research. National Academy Press: Washington DC.

Petersen A, Lupton D. 1996. The new public health: health and self in the age of risk. Sage: London. 
Prochaska J, Velicer WF. 1997. The Transtheoretical Model of Health Behavior Change. American Journal of Health promotion 12: 38-48.

Rose G. 1992. The Strategy of Preventive Medicine. Oxford University Press: Oxford.

Spyrou S. 2011. The limits of children's voices: From authenticity to critical, reflexive representation. Childhood 18: 151-165

Swedish Council on Health Technology Assessment (SBU). 2010. Program för att förebygga psykisk ohälsa hos barn. Report 202, SBU: Stockholm.

Thomas E-M. 2013. DISA-metoden. Available at http://www.disa-metoden.com/ [Accessed 21 may 2013].

Treutiger BM. 2006. Evaluation of the DISA program (Depression In Swedish Adolescents) to prevent depressive symptoms among female adolescents. Exam paper, Karolinska Institutet, Sweden.

Valentine K. 2011. Accounting for agency. Children \& Society 25: 347-358.

Verkuyten M. 2003. Racism, happiness, and ideology. In Analyzing race talk: multidisciplinary approaches to the interview. Van Den Berg H, Wetherell M, Houtkoop-Steenstra H (eds). Cambridge University Press: Cambridge; 138-155.

Wetherell M. 1998. Positioning and interpretative repertoires: conversation analysis and post-structuralism in dialogue. Discourse and Society 9: 387-412.

Wickström A. 2013. From individual to relational strategies: Transforming a manualbased psycho-educational course at school. Childhood 20: 215-228 